\title{
Multiple mating and siring success during natural oestrus in the ewe
}

\author{
P. A. Jewell, S. J. G. Hall and M. M. Rosenberg* \\ Research Group in Mammalian Ecology and Reproduction, Physiological Laboratory, \\ Downing Street, Cambridge CB2 3EG and *Ash Farm, Iddesleigh, Devon EX19 8SQ, U.K.
}

\begin{abstract}
Summary. Ewes were each mated on four separate occasions, at 3,9,15 and $21 \mathrm{~h}$ after the start of oestrus and at each time by a different ram. The progeny were assigned to sires by blood typing, supplemented by resemblance between lambs and rams. The paternity of 64 lambs, born to 41 ewes, was established: 2 were conceived at a 3-h mating, 27 at $9 \mathrm{~h}, 23$ at $15 \mathrm{~h}$ and 12 at $21 \mathrm{~h}$. The optimum time for a ram to inseminate, when in competition with others, is therefore 9-15 h after onset of oestrus, and this finding accords with behavioural observations. Ewes tended to lamb during the same half of the day as that when they had come into oestrus.
\end{abstract}

\section{Introduction}

In many mammalian species successful competition by males for territories or for high social status, sometimes coupled with persistent herding of females, secures a reproductive advantage, and individual males attempt to retain exclusive access to a receptive female by guarding her (Jewell, 1976). Nevertheless, the female may be inseminated by several different males, as has been widely reported for many species of ruminants (see Gibson \& Jewell, 1982, for references). In these circumstances which male is likely to be the successful sire? We decided that it would be appropriate to investigate this question in commercial sheep because farm breeds, feral and wild sheep all show the phenomenon of multiple mating (Hulet, 1966; Geist, 1971; Grubb \& Jewell, 1973).

The number of times that a ewe may be inseminated during oestrus has been reported variously as 6-7 times (Hulet, 1966; Hulet, Blackwell, Ercanbrack, Price \& Wilson, 1962); 12-15 services a day (Lambourne, 1956, quoted by Hulet, Ercanbrack, Price, Blackwell \& Wilson, 1962); or about once an hour (Grubb \& Jewell, 1973; Grubb, 1974; Gibson \& Jewell, 1982). When several rams are kept with a flock more than one ram may inseminate each ewe; indeed, given the opportunity a ewe will seek to be inseminated by several rams during her oestrus (Lindsay \& Fletcher, 1972; Gibson \& Jewell, 1982).

In the feral Soay sheep on St Kilda (Jewell, Milner \& Boyd, 1974) the rams form a dominance hierarchy during the rut and as ewes come into oestrus they may be detected, chased and mounted, first by young rams, but then they are taken over and guarded individually by a dominant ram and are inseminated repeatedly (Grubb \& Jewell, 1973). Towards the end of oestrus, however, the ram may abandon the ewe with whom he had been consorting and then a succession of subordinates mate with her (Grubb, 1974). These observations suggest that the optimum time for a ram to inseminate a ewe, when multiple mating occurs, is during the earlier or middle part of oestrus and not towards the end.

Conception may occur from artificial insemination administered at any time during the natural oestrus of ewes (Amir \& Schindler, 1972), but the only published investigation that we have found of the effective time for fertilization from multiple natural matings in the ewe is that of Slee (1964), who reported that the second ram of two that inseminated a ewe shortly after the start of oestrus was likely to be the successful sire. When 4 rams were used (on a sample of only 10 ewes) the ram at mating time 2 had the greatest success. 
The aim of the present experiment was to determine which ram, of several that may inseminate a ewe during oestrus, is likely to be the successful sire. Given that the timing of matings was set sequentially the results were expected to reveal the optimum time for a ram to mate when in competition with others.

\section{Materials and Methods}

Animals and housing. We carried out the experiment at Ash Farm and its annexe, Furzdon Farm, near Iddesleigh, Devon. Ash Farm has the status of an Approved Breeding Centre of the Rare Breeds Survival Trust (Anon, 1975; Urquhart, 1981) where sheep of a wide variety of breeds are maintained. Photographs of the breeds that we used are given by the National Sheep Association (1982).

Each of the 4 rams chosen (a Suffolk, a Shropshire, a Southdown and a Leicester Longwool) possessed at least one blood group allele (see below) which the others did not and was therefore expected to leave a record of his paternity on a high proportion of the lambs he sired, but the Leicester Longwool had many blood groups in common with the other rams and it was anticipated that he would be the least likely to leave a distinctive record of paternity on a lamb. In addition these breeds each possess distinctive physical features, providing another means of assigning paternity. Electroejaculation of each ram just before the experiment started yielded semen which microscopic examination (J. C. Hindson, personal communication) showed to be of good quality. Oestrus was detected by a teaser ram; teasers were vasectomized Lleyn rams which had been used in previous years and the one in use was exchanged after 8 days.

A total of 54 ewes entered the experiment; 30 were 2- or 3-year-old cross-breds, the progeny of matings between Wensleydale rams and Hebridean, Whitefaced Woodland or Swaledale ewes: the rest were pure-bred, Herdwicks ( 9 ewes) and Manx Loghtans ( 8 ewes) predominating. The ewes were already cyclic when the experiment started. All 54 ewes showed oestrus and the lambing of 49 was observed, so analysis of sex ratio and number of offspring, and timing of oestrus and of lambing were made on these numbers of ewes, although only 41 ewes fulfilled all other procedures necessary for establishing the paternity of lambs (see below).

Detection of oestrus. The ewes were put together in a large covered yard and the 4 rams were penned individually along the sides of the yard. A hay-loft at one end provided an elevated viewing platform. The yard was illuminated at night and a continuous watch kept by 2 observers, day and night, for 18 days (the oestrous cycle of the ewe is about 16 days). The teaser was introduced on 23 October 1983 and the few ewes that were detected immediately as in oestrus were removed to be returned to the experiment a few days later.

The start of oestrus was defined as the moment that a ewe stood to allow the teaser to mount. She was caught immediately, usually before the teaser had achieved an ejaculation, and was put into a holding pen.

Mating procedure. It is generally accepted that oestrus in the ewe lasts for $24-30 \mathrm{~h}$ (Robertson, 1977). To ensure that all ewes would stand for 4 matings we kept procedures within the $24 \mathrm{~h}$. Each ewe was to be inseminated 4 times, each time by a different ram, at intervals of $6 \mathrm{~h}$. There are 24 permutations of the relative presentations of the rams, i.e. 24 possible mating sequences. These mating sequences were written on slips of plastic and one was drawn at random whenever a ewe entered oestrus. If the mating sequence meant that a ram would be required to inseminate one ewe soon after another, the sequence was set aside (to be returned to the draw) and another drawn. There were enough ewes to permit each sequence to be repeated, and the few additional ewes were allotted sequences that had not been completed successfully on the first 2 runs.

Ewes were reluctant to stand to a ram immediately after detection of oestrus and various times were tried on 5 ewes before the adoption as the standard procedure of an initial $3 \mathrm{~h}$ delay from 
detection to first mating: subsequent matings were at 9,15 and $21 \mathrm{~h}$ after the start of oestrus. Each mating was watched (usually by one or 2 observers) and the ram was allowed to give 2 ejaculations, these being signalled by the pronounced pelvic thrust, and head jerk, of the ram. The standard procedure was applied to the remaining 49 ewes.

Of these 49 ewes, 3 refused one or more of the matings allotted to them, and 3 ewes did not conceive during the experiment. The progeny of 43 ewes were therefore available for examination, and these comprised a total of 68 lambs.

Lambing. The ewes lambed in individual pens in a shed, which was dimly lit at night, a 24-h watch being kept at lambing time. The resemblance of lambs to the rams was sometimes recorded at birth, and for all lambs was recorded at about 1 month of age. To find out whether ewes lamb at the same time of day as that when they come into oestrus, the absolute value in minutes of the deviation of lambing time from time of detection of oestrus was calculated for each ewe.

Determination of paternity. A blood sample was taken from each ram and ewe into an individual 10-ml heparinized tube (Vacutainers, by Becton \& Dickinson Ltd) through a single-use 27-gauge needle. Lambs were bled at about 1 month of age using Vacutainers or disposable syringes. Standard procedures (Buis \& Tucker, 1983) were used to investigate the following blood types which are genetically determined and are not sex-linked; haemoglobin, transferrin, and the red cell antigen factors controlled by the A, B, D, M and R-I loci; an additional reagent (V) was included in the tests although it is not known to which locus it belongs.

In determining paternity, priority was given to blood types, but if these were consistent with two alternative rams being the sire then, if possible, the lamb was assigned to one of them on visual appearance.

Statistical methods. All the statistical tests used are described by Siegel (1956), Moore \& Edwards (1965) and Sokal \& Rohlf (1981).

\section{Results}

\section{Completion of procedures}

The mean time interval between the 2 ejaculations that each ram gave at each mating time was $6.7 \mathrm{~min}$; on only 10 occasions were these separated by more than $20 \mathrm{~min}(n=141$, range $1-34 \mathrm{~min})$.

Eleven ewes had had to be withdrawn from the experiment, but this did not vitiate the design, as matings of the remaining 43 ewes were fairly evenly distributed amongst rams and mating times (each ram served at least 9 ewes at each mating time). Of the 25 multiple births, all were sets of twins, and 10 of these were found to be bi-paternal, so mating success was defined as the number of lambs sired rather than the number of ewes impregnated.

\section{Assessment of paternity}

Of the 68 lambs, 52 were unequivocally assigned to sires by blood typing. The blood types of the other 16 lambs were consistent with their having been sired by one of 3 possible rams; 12 could be assigned to a ram on grounds of appearance, leaving 4 to be discarded from the experiment. Two of these were from different lamb pairs so their dams still contributed to the experiment but two were singletons, meaning that the 64 lambs used for the main analysis were the progeny of 41 ewes.

\section{The effect of mating time on siring success}

Table 1 reveals that the first matings, at $3 \mathrm{~h}$, were singularly unsuccessful in giving rise to 
Table 1. Number and sex of lambs conceived from each mating time

\begin{tabular}{lccccc}
\hline & \multicolumn{5}{c}{ Mating time after onset of oestrus } \\
\cline { 2 - 5 } & $3 \mathrm{~h}$ & $9 \mathrm{~h}$ & $15 \mathrm{~h}$ & $21 \mathrm{~h}$ & Total \\
\hline $\begin{array}{l}\text { Paternity assessed } \\
\text { from blood typing }\end{array}$ & 1 & 25 & 19 & 7 & 52 \\
$\begin{array}{l}\text { Paternity assessed } \\
\text { from appearance, } \\
\text { blood typing having } \\
\text { been inconclusive }\end{array}$ & 1 & & & & \\
\begin{tabular}{l} 
Totals (males) \\
\hline
\end{tabular} & $2(0)$ & $27(17)$ & $23(11)$ & $12(6)$ & $64(34)$ \\
\hline
\end{tabular}

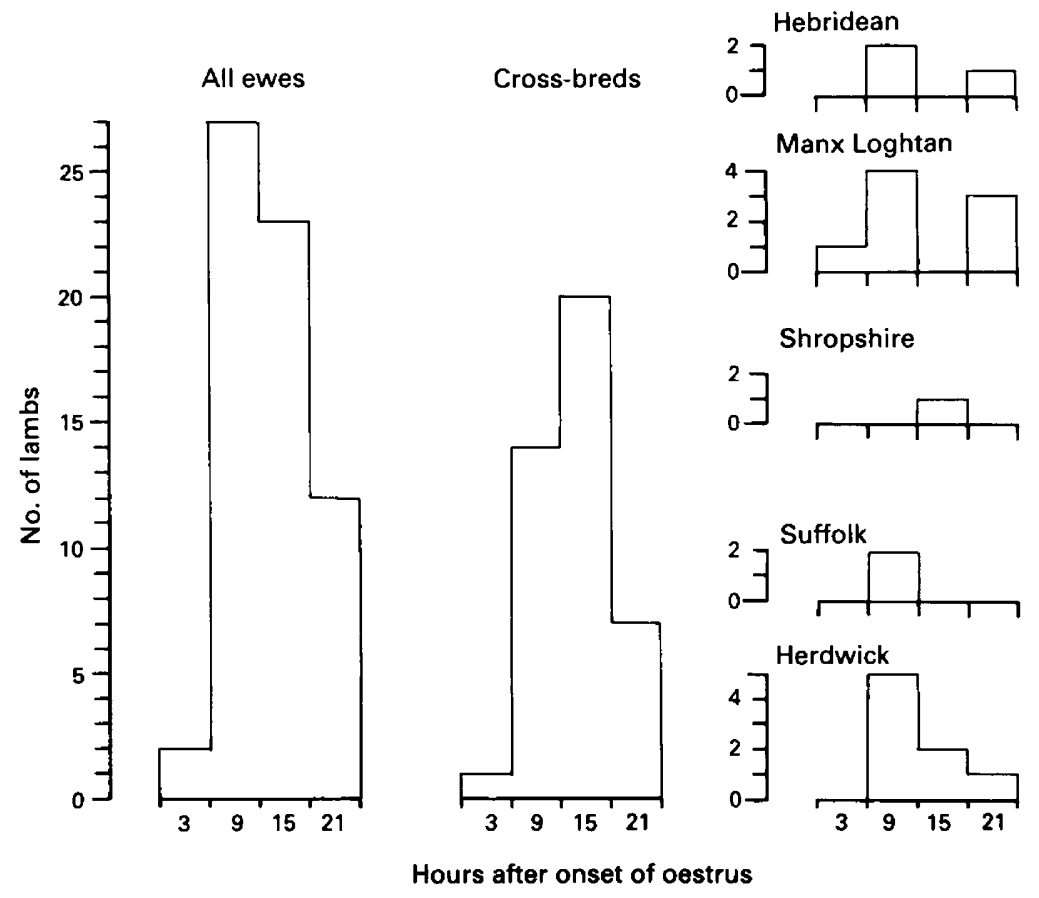

Fig. 1. Numbers of lambs conceived from each mating time, classified by breed of dam.

conceptions. The last mating time, at $21 \mathrm{~h}$, was also significantly less successful than the middle times ( 50 conceptions at 9 and $15 \mathrm{~h}, 12$ conceptions at $21 \mathrm{~h} ; z=-2.52, P<0.01$, binomial test).

A peak of conceptions at the 9-h mating time (Fig. 1), when all ewes were considered together, was largely attributable to pure-breds, since the cross-breds showed a peak at the 15 -h mating time. This difference is significant $\left(\chi^{2}=7 \cdot 24\right.$, d.f. $\left.=2, P<0.05\right)$.

\section{The effect of individual rams}

Rams did not differ in siring success (Fig. 2). The lambs conceived from mating time 1 were discarded from the analysis. A G-test on the column totals showed $(G=1 \cdot 2732$, d.f. $=3$, N.S.) that, overall, siring success of the rams was uniform. A G-test on the body of the table showed 


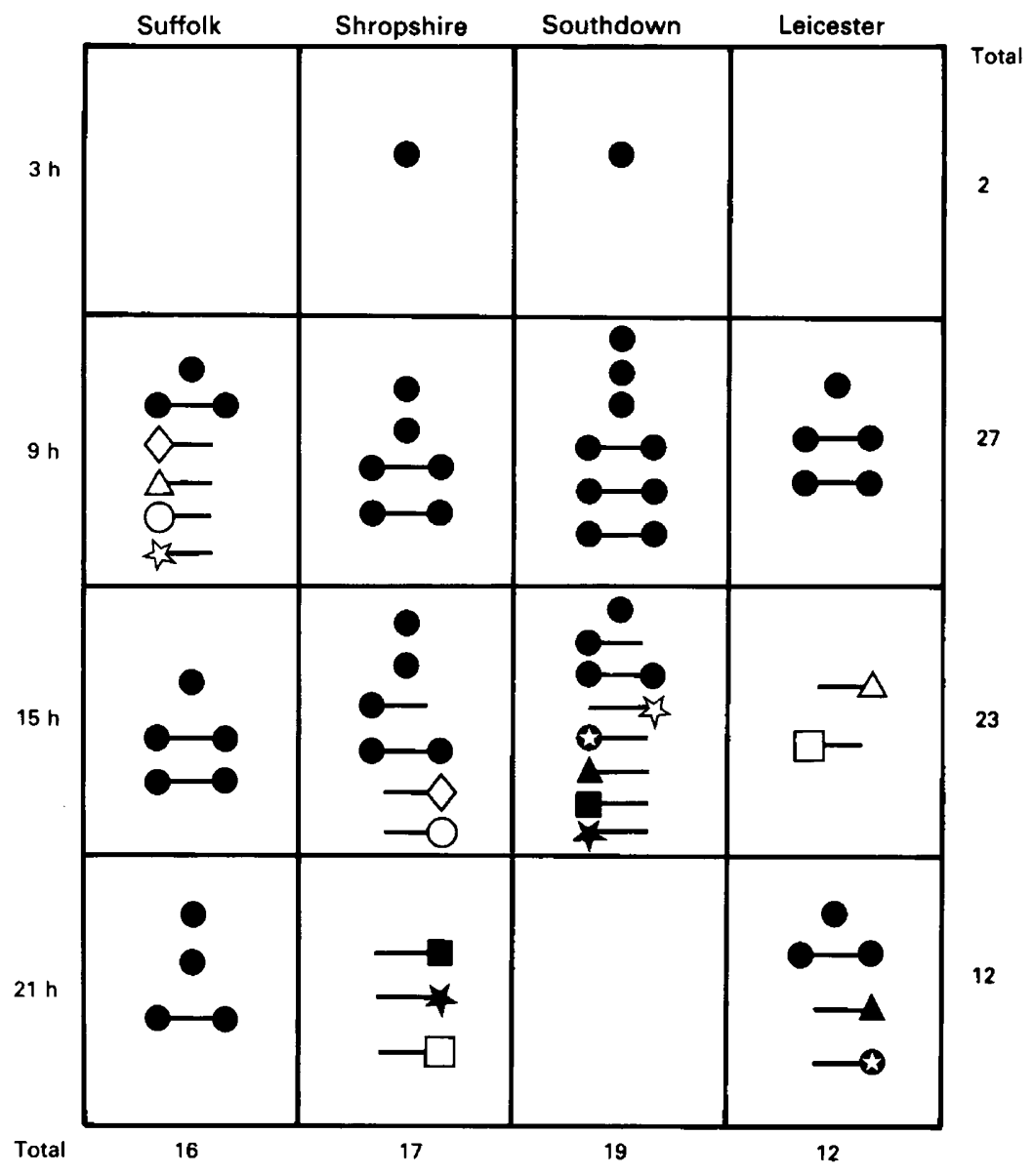

Fig. 2. Lambs sired by the four rams at each mating time: $\bigcirc$ singleton; -1 twins sired by the same ram; -a lamb the sire of whose twin could not be identified; $\mathrm{O}_{-}, \triangle$-etc., lambs of bipaternal twins whose siblings are shown by the same symbol $-\mathrm{O}-\triangle \mathrm{etc}$.

( $\mathrm{G}=12 \cdot 6040$, d.f. $=6, P=0.05$ ) that there was a slight but significant interaction of rams and mating time in determining siring success.

\section{Bi-paternal twins}

In 8 of the 10 pairs of bi-paternal twins, the two sires could be identified, and all 8 were produced from inseminations at adjacent mating times and from all 6 possible combinations of the 4 rams (Fig. 2). The 2 other sets of bi-paternal twins were ones in which the sire of one member of the pair was identified but the sire of the other, while known to be different, could not be positively identified.

\section{Sex ratios and litter sizes}

The 64 lambs whose paternity was established comprised 30 females and 34 males $\left(8 \hat{O}^{\wedge}, 8\right.$, 89 from the Suffolk ram; $6 \delta^{\star} \sigma^{*}, 11$ + 9 from the Shropshire ram; $14 \sigma^{\star} \sigma^{*}, 5 \circ q$ from the Southdown ram; $60^{\circ}, 600+$ from the Leicester ram). The value for the Southdown ram is a significant departure from 

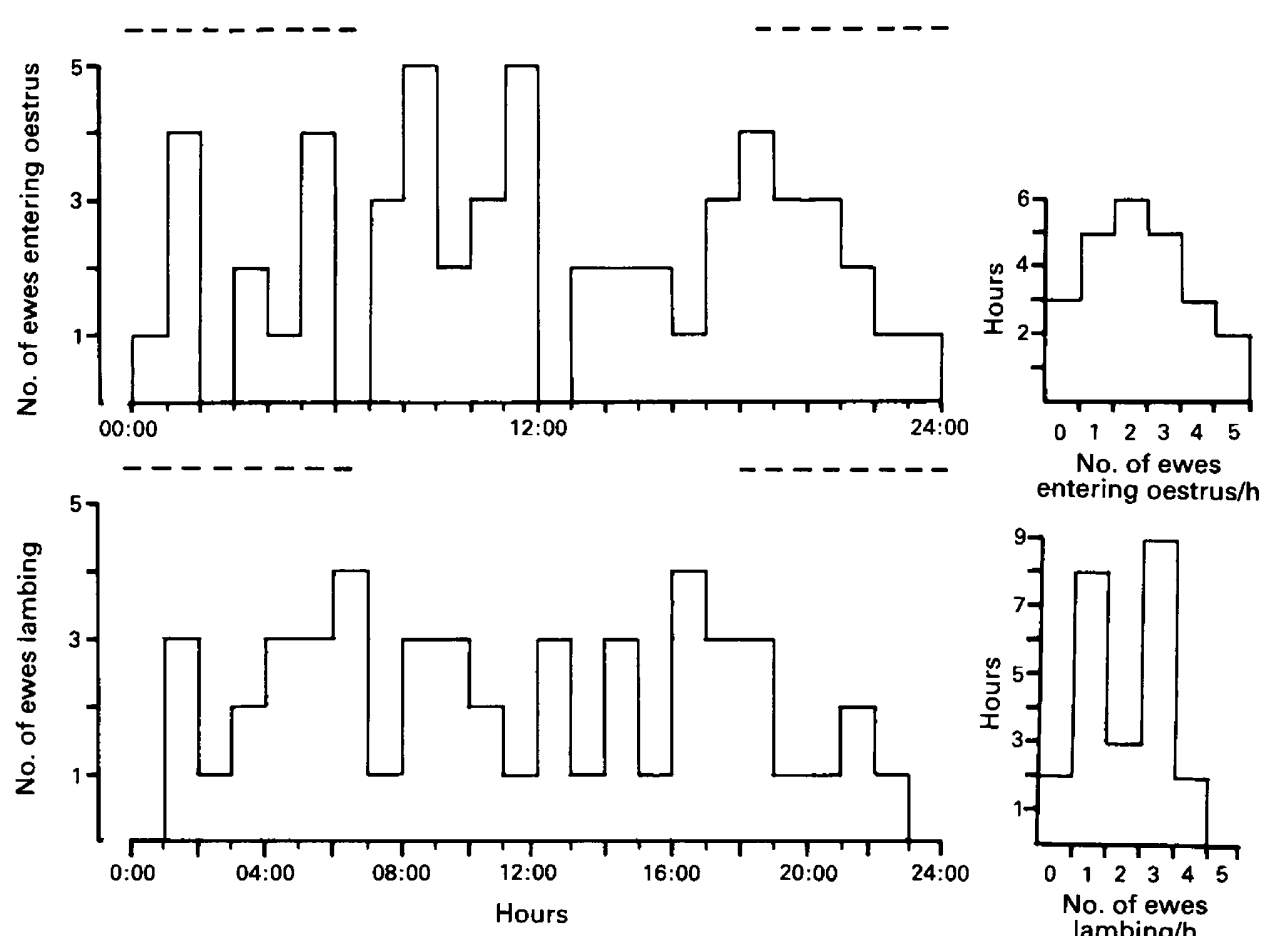

Fig. 3. Frequency distributions of ewes starting oestrus and lambing during each hour of the day, and the same data showing the distribution of hours with 0 to 5 ewes entering oestrus or lambing. The broken bar indicates artificial light for observations.

a $1: 1$ sex ratio (binomial test, $P<0.05$ ). Sex ratios did not show any dependence on mating time (Table 1).

If all lambs are considered, regardless of whether paternity was established and whether their dams conformed with the standard mating procedure, the proportions of the sexes were 42 females to 39 males ( 79 lambs born to 49 ewes, with another 2 taken as fetuses from a ewe that had had to be slaughtered). Of the 30 cross-bred ewes, 23 had twins. Of the 21 pure-bred ewes, only 7 had twins. This difference is significant $\left(\chi^{2}=9.58\right.$, d.f. $\left.=1, P<0.01\right)$ and all 10 pairs of bi-paternal twins were born to cross-bred ewes.

\section{Timing of oestrus and of parturition}

The 49 ewes were classified as entering oestrus during the $12 \mathrm{~h}$ before noon or during the other half of the day: 35 lambed during the same half of the day as that in which their oestrus started; this is a significantly higher proportion than would be expected $(\mathrm{z}=2.857, P<0.01$, binomial test $)$. Cross-breds and pure-breds differed significantly in deviation (min) of lambing time from time of entering oestrus (cross-breds: $\mathrm{N}=28$, mean $=365 \cdot 7$; pure-breds: $\mathrm{N}=21$, mean $=214 \cdot 9$; $\left.F_{(1,47)}=8.58, P<0.01\right)$.

Oestrus showed no tendency to start at any particular time; the frequencies followed a Poisson distribution $\left(\chi^{2}=0 \cdot 19\right.$, d.f. $=2$, N.S.) (Fig. 3). There was no obvious pattern to the distribution of lambing times and they did not conform to the Poisson distribution $\left(\chi^{2}=5.03\right.$, d.f. $\left.=1, P<0.05\right)$. 


\section{Discussion}

Our results clearly demonstrate that when multiple mating occurs during a ewe's oestrus a ram is more likely to become a successful sire by impregnating the ewe during a definitive period. Matings at early times are not effective and this is a striking result that we had not anticipated in our original hypothesis. It does, however, fit what is to be seen in the field since in many mammals young and subordinate males are often the first to find and mount oestrous females. Older dominant males may only attempt to take over the females at a later stage. This has been recorded in our own work on feral Soay sheep and Chillingham cattle, and has been seen in free-ranging pigs (D. G. M. Wood-Gush, personal communication).

In our results the high success of natural inseminations at $9 \mathrm{~h}$ and $15 \mathrm{~h}$ after the start of oestrus and the significantly lower success at $21 \mathrm{~h}$ support our original hypothesis. Under natural conditions these effects could be exaggerated by more frequent mating. The number of spermatozoa deposited is important and fertility is known to be directly related to number of services (Dunlop \& Tallis, 1964; Mattner \& Braden, 1967; Entwistle \& Martin, 1972). Many inseminations by a consorting male at mid-oestrus, therefore, would be likely to overwhelm ejaculations deposited later. Clearly, mate guarding is important to reproductive success in sheep, and our results are probably applicable to other polygamous mammals.

Our conclusions substantiate those of Slee (1964) (see 'Introduction'). Dziuk (1970) investigated double mating $4 \mathrm{~h}$ apart by rams of 2 distinctive breeds and found that from 15 to $7 \mathrm{~h}$ before ovulation the first ram was the successful sire twice as frequently as the second ram. Oestrus and ovulation were controlled by progesterone and hCG in the experiment of Dziuk (1970) and Robinson $(1967,1982)$ has emphasized that neither phenomenon may be normal under hormone treatment. Nevertheless, if in our experiment ovulation occurred near to $24 \mathrm{~h}$ after the start of oestrus then the results of Dziuk (1970) would be conformable with those obtained in our more natural conditions. Schindler \& Amir (1973), using a single administration of AI at various times during natural oestrus, found the highest conception rate between 16 and $24 \mathrm{~h}$ after the onset of oestrus.

In certain circumstances rams may lose fertility through repeated mating. In rams that were worked hard, 8 being expected to impregnate 400 ewes, deterioration in semen characteristics occurred (Simpson \& Edey, 1979). Hulet (1966) found that rams could impregnate 10 ewes a day over a 4-day period. Synnott, Fulkerson \& Lindsay (1981) found that some rams, whose sexual motivation was maintained by provision of fresh ewes, ejaculated from 11 to 17 times per $24 \mathrm{~h}$, with adequate sperm counts still being recorded after 6 days, while in other rams, the number of spermatozoa per ejaculate was reduced below the level required for adequate fertility (Fulkerson, Synnott \& Lindsay, 1982). Raadsma \& Edey (1984) found that flock fertility was not depressed when rams were giving 6-8 matings a day over 17 days. In many of these reports the demands made on the fertilizing ability of the rams were much more severe than in our experiment in which each ram was required to ejaculate 108 times in 18 days, i.e. about 6 times a day. We consider it unlikely that our rams suffered any reduction in fertility.

We found no evidence for any interference effect among rams. There was a statistically significant ram-mating time interaction, i.e. some rams may be disproportionately successful at some mating times, but in a free-ranging flock any such effect is likely to be obscured. The fact that bi-paternal twins were produced by all possible combinations of the 4 rams (Fig. 1) shows that the spermatozoa of each ram were able to function effectively in the presence of the semen of the other rams, suggesting that the spermatozoa had to compete to fertilize each egg separately and independently of whether 1, 2 or more eggs were shed. In our experiment it is possible that a long interval between ovulations, in those ewes giving multiple births, could have contributed to the production of bi-paternal twins. Intervals of up to $6 \mathrm{~h}$ have been recorded (Whyman, Johnson, Knight \& Moore, 1979).

Langford \& Marcus (1982) have shown that fertility is fully maintained by ram spermatozoa 
suspended in pooled seminal plasma, and it is known that the mixed semen of rams is efficacious (Robinson, Moore, Holst \& Smith, 1967). The lack of relationship between the sex of lambs and the time of insemination (Table 1) shows that the sex chromosome of the spermatozoa had no detectable influence on the outcome of such competition.

Comparisons between the cross-bred and the pure-bred ewes suggest that there are differences amongst ewes in timing optima, and such differences amongst breeds have been reported (Kelley, 1937). The ewes from primitive breeds (Herdwick, Manx Loghtan and Hebridean) tended to conceive to the mating at $9 \mathrm{~h}$ (Fig. 2) and so may have ovulated slightly earlier.

We obtained, incidentally, some information on the time of day at which ewes come into oestrus and at which they lamb. Both phenomena were found to be likely to occur at any time. Births tended to be grouped in time; this was not the case with start of oestrus (Fig. 3). Robertson \& Rakha (1965) found that their sample of Cheviot ewes tended to come into oestrus around sunrise or sunset, and George (1969) and Lindahl (1964) found that most births took place during the hours of daylight. Schindler \& Amir (1972) found, as we did, that there was no preferred time for the onset of oestrus. However, the time of day at which oestrus started could be related to the time of day when parturition occurs. Numbers are too small in this experiment for effects of breed, parity, or litter size to be investigated, but the significant difference between cross-breds and pure-breds suggests further experimentation on this phenomenon, which has not to our knowledge been described before.

We thank Dr E. M. Tucker, AFRC Institute of Animal Physiology, Babraham, who arranged for the transferrin and red cell antigen typing; Mr J. C. Hindson, BVSc, MRCVS, Mr A. Boughey and $\mathrm{Mr}$ and Mrs J. Moses who looked after the sheep; and the many volunteers who assisted with the recording and handling of the animals, and who helped us to maintain uninterrupted watch for 18 days and nights.

\section{References}

Anon. (1975) Ash Farm. Ark 2, 283-285.

Amir, D. \& Schindler, H. (1972) The conception rate of ewes after artificial insemination at different times during oestrus. J. Reprod. Fert. 28, 261-264.

Buis, R. C. \& Tucker, E. M. (1983) Relationships between rare breeds of sheep in the Netherlands as based on blood typing. Anim. Blood Gps Biochem. Genet. 14, 17-26.

Dunlop, A.A. \& Tallis, G.M. (1964) The effects of length of oestrus and number of inseminations on the fertility and twinning rate of the Merino ewe. Aust. J. agric. Res. 15, 282-288.

Dziuk, P. (1970) Estimation of optimum time for insemination of gilts and ewes by double-mating at certain times relative to ovulation. J. Reprod. Fert. 22, 277-282.

Entwistle, K.W. \& Martin, I.C.A. (1972) Effects of the number of spermatozoa and of volume of diluted semen on fertility in the ewe. Aust. J. agric. Res. 23, $467-472$.

Fulkerson, W.J., Synnott, A.L. \& Lindsay, D.R. (1982) Numbers of spermatozoa required to effect a normal rate of conception in naturally mated Merino ewes. $J$. Reprod. Fert. 66, 129-132.

Geist, V. (1971) Mountain Sheep: A Study in Behavior and Evolution. University of Chicago Press. Chicago.
George, J.M. (1969) Variation in the time of parturition of Merino and Dorset Horn ewes. J. agric. Sci., Camb. 73, 295-299.

Gibson, R.M. \& Jewell, P.A. (1982) Semen quality, female choice and multiple mating in domestic sheep: a test of Trivers' sexual competence hypothesis. Behaviour 80, 9-31.

Grubb, P. (1974) Social organisation of Soay sheep and the behaviour of ewes and lambs. In Island Survivors: the Ecology of the Soay Sheep of St. Kilda, pp. 131159. Eds P. A. Jewell, C. Milner \& J. M. Boyd. Athlone Press, London.

Grubb, P. \& Jewell, P.A. (1973) The rut and the occurrence of oestrus in the Soay sheep on St. Kilda. $J$. Reprod. Fert., Suppl. 19, 491-502.

Hulet, C.V. (1966) Behavioural, social and psychological factors affecting mating time and breeding efficiency in sheep. J. Anim. Sci. 25, Suppl., 5-20.

Hulet, C.V., Blackwell, R.L., Ercanbrack, S.K., Price, D.A. \& Wilson, L.O. (1962) Mating behavior of the ewe. J. Anim. Sci. 21, 870-874.

Hulet, C.V., Ercanbrack, S.K., Price, D.A., Blackwell, R.L. \& Wilson, L.O. (1962) Mating behavior of the ram in the one-sire pen. J. Anim. Sci. 21, 857-864.

Jewell, P.A. (1976) Selection for reproductive success. In Reproduction in Mammals. 6. The Evolution of 
Reproduction, pp. 71-109. Eds C. R. Austin \& R. V. Short. Cambridge University Press.

Jewell, P.A., Milner, C. \& Boyd, J.M. (Eds) (1974) Island Survivors: The Ecology of the Soay Sheep of St. Kilda. Athlone Press, London.

Kelley, R.B. (1937) Studies in fertility of sheep. Bull. Coun. sci. industr. Res. Aust. No. 112,67 pp.

Langford, G.A. \& Marcus, G.J. (1982) Influence of sperm number and seminal plasma on fertility of progestagen-treated sheep in confinement. J. Reprod. Fert. 65, 325-329.

Lindahl, I.L. (1964) Time of parturition in ewes. Anim. Behav. 12, 231-234.

Lindsay, D.R. \& Fletcher, I.C. (1972) Ram seeking activity associated with oestrus behaviour in ewes. Anim. Behav. 20, 452-456.

Mattner, P.E. \& Braden, A.W.H. (1967) Studies in flock mating of sheep. 2. Fertilization and prenatal mortality. Aust. J. exp. Agric. Anim. Husb. 7, 110-116.

Moore, P.G. \& Edwards, D.E. (1965) Standard Statistical Calculations. Pitman, London.

National Sheep Association (1982) British Sheep. NSA, Tring.

Raadsma, H.W. \& Edey, T.N. (1984) Dynamics of paddock mating of rams in conventional and intensified mating systems. In Reproduction in Sheep, pp. 50-52. Eds D. R. Lindsay \& D. T. Pearce. Cambridge University Press.

Robertson, H.A. (1977) Reproduction in the ewe and the goat. In Reproduction in Domestic Animals, 3rd edn, pp. 475-498. Eds H. H. Cole \& P. T. Cupps. Academic Press, New York.

Robertson, H.A. \& Rakha, A.M. (1965) Time of onset of oestrus in the ewe. J. Reprod. Fert. 10, 271-272.

Robinson, T.J. (Ed.) (1967) Control of the Ovarian Cycle in Sheep. Sydney University Press, Sydney.

Robinson, T.J. (1982) The magic of Hammond. $J$. Reprod. Fert. 66, 397-410.
Robinson, T.J., Moore, N.W., Holst, P.J. \& Smith, J.F. (1967) An evaluation of several progestagens administered in intravaginal sponges for the synchronization of oestrus in the entire cyclic Merino ewe. In The Control of the Ovarian Cycle in Sheep, pp. 76-101. Ed. T. J. Robinson. Sydney University Press, Sydney.

Schindler, H. \& Amir, D. (1972) Length of oestrus, duration of phenomena related to oestrus, and ovulation time in the local fat-tailed Awassi ewe. J. agric. Sci., Camb. 78, 151-156.

Schindler, H. \& Amir, D. (1973) The conception rate of ewes in relation to sperm dose and time of insemination. J. Reprod. Fert. 34, 191-196.

Siegel, S. (1956) Nonparametric Statistics for the Behavioral Sciences. McGraw-Hill Kogakusha, Tokyo.

Simpson, H. \& Edey, T.N. (1979) Changes in physical condition and ejaculate characteristics in paddockmated rams. Aust. vet. $J$. 55, 225-228.

Slee, J. (1964) Some aspects of multiple-mating and superovulation in sheep. J. agric. Sci., Camb. 63, 403-408.

Sokal, R.R. \& Rohlf, F.J. (1981) Biometry, 2nd edn. W. H. Freeman, San Francisco.

Synnott, A., Fulkerson, W. J. \& Lindsay, D.R. (1981) Sperm output by rams and distribution amongst ewes under conditions of continual mating. $J$. Reprod. Fert. 61, 355-361.

Urquhart, J. (1981) Ash Farm. Ark 8, 18-21.

Whyman, D., Johnson, D.L., Knight, T.W. \& Moore, R.W. (1979) Intervals between multiple ovulations in PMSG-treated and untreated ewes and the relationship between ovulation and oestrus. $J$. Reprod. Fert. $55,481-488$.

Received 17 July 1985 